Saudi Journal of Oral and Dental Research

Abbreviated Key Title: Saudi J Oral Dent Res

ISSN 2518-1300 (Print) |ISSN 2518-1297 (Online)

Scholars Middle East Publishers, Dubai, United Arab Emirates

Journal homepage: http://scholarsmepub.com/sjodr/

\title{
Attitude, Awareness about the Periodontal Surgery among the Population of Jizan, in Saudi Arabia
}

Sara Mufarej Aljadaani*, Fatima Sultana

Ministry of Health, Saudi Arabia

DOI: $10.36348 /$ sjodr.2020.v05i01.007

| Received: 01.01.2020 | Accepted: 10.01.2020 | Published: 17.01.2020

*Corresponding author: Sara Mufarej Aljadaani

\section{Abstract}

The periodontal disease is basically a multi-factorial disease that is impacted by many components of the periodontal tissue. If the periodontal disease is left untreated it can cause many severe complications of the oral cavity. The plaque can be prevented by maintaining proper oral hygiene and also visiting the dentist. The attitude and awareness of the people about the periodontal surgery is of utmost importance. The main aim of this study was study the attitude and awareness about the periodontal surgery among the population of Jizan in Saudi Arabia. The population of Jizan answered the questionnaire related to the attitude and awareness about the periodontal surgery. Periodontitis may lead to high risk of multiple tooth loss which eventually lead to edentulism. The results of this survey showed that $32(32.8 \%)$ of the participants were in the age group of 31-40 years and majority of the people were females about 59 (60.2\%). This survey about the attitude and awareness about the periodontal surgery is a stepping stone in spreading the knowledge and awareness in the population of Jizan, Saudi Arabia.

Keywords: periodontal disease, periodontitis, plaque, multi-factorial, edentulism, Oral hygiene.

Copyright @ 2020: This is an open-access article distributed under the terms of the Creative Commons Attribution license which permits unrestricted use, distribution, and reproduction in any medium for non-commercial use (NonCommercial, or CC-BY-NC) provided the original author and source are credited.

\section{INTRODUCTION}

The absence of signs and symptoms in the periodontal tissues is defined as the perfect periodontal health. The periodontal disease is basically a multifactorial disease that is impacted by many components of the periodontal tissue. This multi-factorial disease can affect the remote organ in the body leading to undesired events inside the body.

It was confirmed by the National Health and nutrition examination survey the prevalence of periodontal diseases among the people is about $50 \%$ in USA [1]. The prevalence of periodontal disease was with patients suffering from type 2 Diabetes mellitus that was found in a study carried out by Kumar et al. in India [2]. The prevalence of periodontal disease in the Al-Baha city was reported by Al Qahtani et al. in Saudi Arabia with prevalence of gingivitis of $48.8 \%$ [3].

If the periodontal disease is left untreated it can cause many severe complications of the oral cavity like the mobility of the teeth, bone resorption, tooth loss. In the previous literature it was found that many studies have been reported on the relationship between the periodontal disease and the systemic disease; especially the relationship between the periodontal disease with the diabetes mellitus, cardiovascular diseases, osteoporosis and also the adverse pregnancy outcomes [4].

A significant etiological factor behind the periodontal disease is the plaque; this is a biofilm containing the micro-organism [5]. The other risk factors associated with the diseases are poor physical activity, poor diet and nutrition, the excessive use of tobacco, over-consumption of alcohol, obesity, psychosocial stress, inadequate personal oral hygiene and the overall health [6]. The plaque can be prevented by maintaining proper oral hygiene and also visiting the dentist [7-9]. This can also be considered as the effective preventive measures against the deposition of plaque on teeth.

The control and prevention of the periodontal disease is highly influenced by the personal oral hygiene and behavior [10]. The attitude and awareness of the people about the periodontal surgery is of utmost importance. No research was carried out and reported in the city of Jizan, hence we selected this topic for our study in Jizan. The main aim of this study was to study the attitude and awareness about the periodontal surgery among the population of Jizan in Saudi Arabia. 


\section{METHODOLOGY}

A pre-formulated, pre-validated questionnaire was distributed among the general population of Jizan, in Saudi Arabia. The population of Jizan answered the questionnaire related to the attitude and awareness about the periodontal surgery. The survey was carried out in the year 2019.

This pre-designed questionnaire was first formulated in the English language and also translated to Arabic. This questionnaire in both Arabic and English language was distributed online using the online Application called Typeform. The inclusion factor of this study was the population residing in Jizan and a human survey. The exclusion factor was population residing in other cities of Saudi Arabia.

The data that was collected from the questionnaire was analysed using the computer software
Statistical package for social sciences that is SPSS 16 . The frequencies and percentages of the responses from the general population in Jizan in Saudi Arabia were done using the $\mathrm{P}$ value equal to or less than 0.05 . The descriptive statistics was attained and the mean, standard deviation and frequency distribution was calculated.

\section{RESULTS}

Demographic Data

About 98 people answered the questionnaire belonging to Jizan. The demographic data of these 98 people reported that about $32(32.8 \%)$ were in the age group of 31-40 years. Majority of the people were females about $59(60.2 \%)$ and $39(39.8 \%)$ were males. $26(26.5 \%)$ were bachelor degree holder, $21(21.4 \%)$ had secondary school degree, $15(15.3 \%)$ had diploma degree, $22(22.5 \%)$ were master degree holder, 12 $(12.3 \%)$ had no education and $2(2 \%)$ were Ph.D holder.

Table-1: Showing demographic characters

\begin{tabular}{|l|l|l|}
\hline DEMOGRAPHIC CHARACTERS & FREQUENCY & PERCENTAGE \\
\hline Age & & \\
$19-30$ years & 15 & \\
31 - 40 years & 32 & 15.3 \\
41 - 50 years & 11 & 32.8 \\
<18 years & 26 & 11.2 \\
51 - 60 years & 9 & 26.5 \\
$>$ 61 years & 5 & 9.1 \\
& & 5.1 \\
\hline Gender & 59 & \\
Female & 39 & 60.2 \\
Male & & 39.8 \\
\hline Qualification & \\
Bachelor Degree & 26 & 26.5 \\
Secondary School & 21 & 21.4 \\
Diploma degree & 15 & 15.3 \\
Master's - Board degree specialist & 22 & 22.5 \\
No Education I don't hold a degree yet & 12 & 12.3 \\
Ph.D & 2 & 2.0 \\
\hline
\end{tabular}

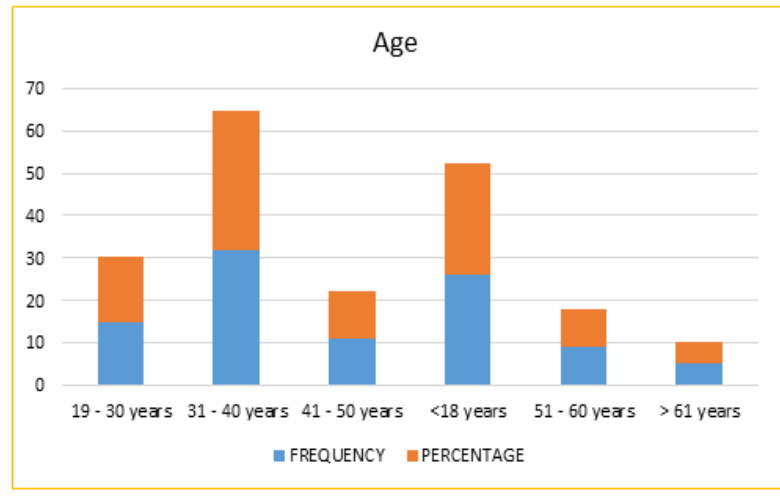

Graph-1: Showing Age group frequency

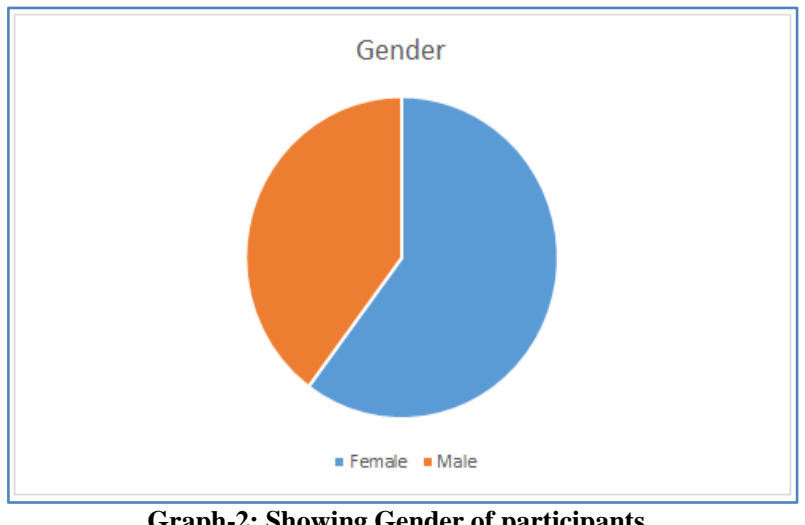

Graph-2: Showing Gender of participants 


\section{Attitude and Knowledge about periodontal surgery}

$75(76.5 \%)$ feels that periodontal diseases is preventable, $45(45.9 \%)$ thinks that periodontal disease is a genetic disease. $62(63.2 \%)$ feels that periodontal disease can lead to pre-term deliveries during pregnancy to some extent. $43(43.9 \%)$ of the people are aware of the gingivial swelling that occurs during the pregnancy to some extent. $71(72.4 \%)$ of the people thinks that the gingivial swelling is due to the growth of the bacteria in the oral cavity. $55(56.1 \%)$ of the population in Jizan thinks that diabetes is a risks factor for periodontal disease. $67(68.4 \%)$ thinks that smoking can effect the healing process after the periodontal surgery to some extent. $78(79.6 \%)$ of the population feels that scaling could cause removal of the enamel to some extent.

Table-2: Showing the attitude of the participants about periodontal surgery

\begin{tabular}{|l|l|l|l|}
\hline ATTITUDE ABOUT PERIODONTAL SURGERY & YES & TO SOME EXTENT & NO \\
\hline Do you think that periodontal disease is preventable? & $75(76.5 \%)$ & $21(21.4 \%)$ & $2(2.1 \%)$ \\
\hline Do you think that periodontal disease is a genetic disease? & $15(15.3 \%)$ & $45(45.9 \%)$ & $38(38.8 \%)$ \\
\hline $\begin{array}{l}\text { Do you think that periodontal disease can lead to pre-term } \\
\text { deliveries during pregnancy }\end{array}$ & $26(26.5 \%)$ & $62(63.2 \%)$ & $10(10.3 \%)$ \\
\hline $\begin{array}{l}\text { Are you aware of the gingivial swelling that occurs during } \\
\text { pregnancy? }\end{array}$ & $36(36.7 \%)$ & $43(43.9 \%)$ & $19(19.4 \%)$ \\
\hline $\begin{array}{l}\text { Do you think that gingivial swelling is due to the bacterial } \\
\text { growth? }\end{array}$ & $71(72.4 \%)$ & $24(24.5 \%)$ & $3(3.1 \%)$ \\
\hline $\begin{array}{l}\text { Do you think that diabetes is a risks factor for periodontal } \\
\text { disease? }\end{array}$ & $55(56.1 \%)$ & $23(23.5 \%)$ & $20(20.4 \%)$ \\
\hline $\begin{array}{l}\text { Do you think that smoking effects the healing process post } \\
\text { periodontal surgery? }\end{array}$ & $14(14.3 \%)$ & $67(68.4 \%)$ & $17(17.3 \%)$ \\
\hline $\begin{array}{l}\text { Do you think that you should visit the dentist post } \\
\text { periodontal surgery? }\end{array}$ & $39(39.8 \%)$ & $54(55.1 \%)$ & $4(4.1 \%)$ \\
\hline Do you think that scaling can cause removal of enamel? & $9(9.2 \%)$ & $78(79.6 \%)$ & $11(11.2 \%)$ \\
\hline $\begin{array}{l}\text { Do you think that a good periodontal surgery can increase } \\
\text { the life span of the teeth? }\end{array}$ & $22(22.5 \%)$ & $69(70.4 \%)$ & $7(7.1 \%)$ \\
\hline $\begin{array}{l}\text { Do you think that elimination of gingivial pockets is a } \\
\text { sign of good periodontal surgery? }\end{array}$ & $72(73.5 \%)$ & $24(24.5 \%)$ & $2(2.0 \%)$ \\
\hline $\begin{array}{l}\text { Do you think that stop of the gingivial bleeding is the } \\
\text { result of a perfect periodontal disease? }\end{array}$ & $81(82.6 \%)$ & $6(6.1 \%)$ & $1(1.3 \%)$ \\
\hline $\begin{array}{l}\text { According to you reduction in the mobility of the teeth is } \\
\text { a sign for good periodontal surgery? }\end{array}$ & $68(69.4 \%)$ & $19(19.4 \%)$ & $11(11.2 \%)$ \\
\hline $\begin{array}{l}\text { Do you think that reccurence of the periodontal disease is } \\
\text { due to instrumental/patient related/doctor related errors? }\end{array}$ & $80(81.6 \%)$ & $8(8.2 \%)$ & $10(10.2 \%)$ \\
\hline
\end{tabular}

\section{Radar Figure showing the attitude of the participants towards periodontal surgery}

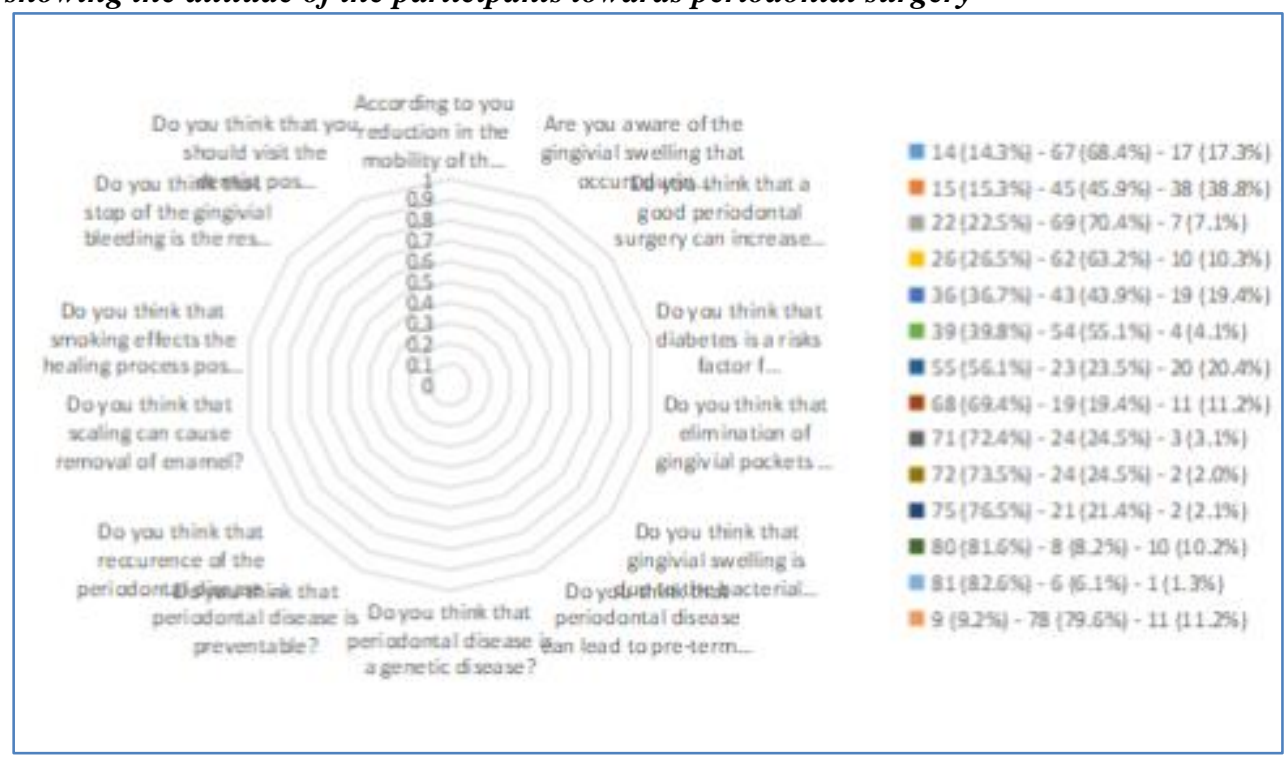

About $54(55.1 \%)$ thinks that the people should visit their dentist after the periodontal surgery. $69(70.4 \%)$ of the Jizan population thinks that the life span of the teeth can be increased to some extent after a good periodontal surgery. $72(73.5 \%)$ of the people thinks that the gingivial pockets can be eliminated 
completely after a good periodontal surgery. $81(82.6 \%)$ thinks that the stop of gingivial bleeding is the result of a perfect periodontal disease. Around 68 (69.4\%) thinks that a good periodontal surgery can result in the reduction of teeth mobility. $80(81.6 \%)$ of the population of Jizan thinks that the recurrence of the periodontal disease can occur due to instrumental or patient related or doctor related errors.

\section{DISCUSSION}

According to the Guinness World Records of 2001 periodontal disease that consists of gingivitis and periodontitis is the most common disease of mankind [Guinness World Records 2001] [12]. According to the Global burden of disease study, periodontitis is the sixth most prevalent disease [14]. It is the major cause of tooth loss in the adult population. Periodontitis may lead to high risk of multiple tooth loss which eventually lead to edentulism. Edentulism may cause trouble with the masticatory functioning, thereby affecting the nutrition and hence the quality of life and also the selfesteem of the patient.

According to Jepsen et al. 2017 he periodontal disease is found mostly in the age group between 30 to 40 years and will keep on increasing with the growing age [15]. Periodontitis is related with heart diseases, diabetes, cancer and chronic respiratory diseases and hence leading to about two-thirds of death rate with them. According to the United Nations 2011. the increased risk of periodontitis may be due to factors like smoking, obesity, physical inactivity and poor nutrition.

Good oral hygiene like using of toothbrush and certain cleaning aids like dental floss can help prevent the periodontal disease by lowering the risk of formation of the dental biofilms (plaque). The early signs and symptoms of the periodontitis are gingival bleeding, halitosis and reduction in the gingival margin. It can also be prevented by the early diagnosis of the Periodontitis, followed by successful treatment and then the life-long secondary prevention to avoid reccurence.

This present study is about the attitude and Awareness of the population residing in Jizan in Saudi Arabia about periodontal surgery. This study was carried out in order to identify the periodontal health literacy rate. According to Chapel et al. 2015, periodontitis is a preventable disease that could be managed by promoting the healthy lifestyles of the population [16]. Initially the periodontal disease should be treated by removing the biofilm of plaque from the super and the sub gingival tissues and then maintaining the appropriate levels of the plaque control and the gingival inflammation and the formation of periodontal pockets [17].
The periodontal pockets can be corrected by the surgery of the anatomical lesion that is caused by the periodontal disease. After the periodontal surgery, oral hygiene is to be maintained that can minimise the recurrence of the periodontal disease [18]. Further, the periodontal surgery needs to be monitored by the supervision of the periodontists. The case should be provided by the periodontist by giving the patient comprehensive advice on the full spectrum treatment and management of the periodontal disease. The periodontist may carry out flap surgery and regenerative periodontal surgery in order to manage the deep residual periodontal pockets, Ridge deformities and masticatory dysfunction with dental implant. The information about the care and follow up post the periodontal surgery is of utmost importance because proper care can avoid the recurrence of he disease.

\section{CONCLUSION}

This study shows that most of the people residing in Jizan is aware about the periodontal surgery. The results of this survey showed that $32(32.8 \%)$ of the participants were in the age group of 31-40 years and majority of the people were females about $59(60.2 \%)$. $75(76.5 \%)$ feels that periodontal diseases is preventable, $45(45.9 \%)$ thinks that periodontal disease is a genetic disease. $78(79.6 \%)$ of the population feels that scaling could cause removal of the enamel to some extent. $67(68.4 \%)$ thinks that smoking can affect the healing process after the periodontal surgery to some extent. About $54(55.1 \%)$ thinks that the people should visit their dentist after the periodontal surgery. 69 (70.4\%) of the Jizan population thinks that the life span of the teeth can be increased to some extent after a good periodontal surgery.

With poor knowledge and awareness about the periodontal surgery can increase the prevalence of the periodontitis. This survey showed that the awareness about the periodontitis and the periodontal surgery is very important factor that affects the the attitude and behaviour of the population. The study outcomes are good about the knowledge and attitude of the population in Jizan about the periodontal surgery. This survey about the attitude and awareness about the periodontal surgery is a steppingstone in spreading the knowledge and awareness in the population of Jizan, Saudi Arabia. Further research and surveys need to be carried out in other cities of Saudi Arabia, to determine the attitude and awareness about the periodontal surgery.

\section{LIMITATIONS}

This study was carried out only in Jizan and was not carried out in other cities of Saudi Arabia this is one of the major limitations to the study. 


\section{ACKNOWLEDGEMENT}

We would like to take the gratitude to thank the population of Jizan for taking part in this survey.

\section{ETHICAL CONSIDERATIONS}

Compliance with ethical standards

Ethical approval: This article contains survey with human participants performed by all the participants of this research.

Conflict of interest: The authors do not have any commercial associations that might pose or create a conflict of interest with information presented in this communication. No intramural or extramural funding supported any aspect of this work.

\section{REFERENCES}

1. Watt, R.G., Petersen, P.E.(2012). Periodontal health through public health - The case for oral health promotion. Periodontol; 60:147-55.

2. Kumar, A., Pandey, M.K., Singh, A., Mittra, P., Kumar, P. (2013). Prevalence and severity of periodontal diseases in type 2 diabetes mellitus of Bareilly region (India) Int $\mathbf{J}$ Med Sci Public Health, 2:77-83.

3. Al Qahtani, N.A., Joseph, B., Deepthi, A., Vijayakumari, B.K.(2017). Prevalence of chronic periodontitis and its risk determinants among female patients in the Aseer region of KSA. J Taibah Univ Med Sci, 12:241-8.

4. Grönbeck, I., Hägglin, C., Gahnberg, L., Andersson, P. (2017). Factors Affecting Older Persons' Ability to Manage Oral Hygiene. A Qualitative Study. JDR Clinic \& Trans Res, 2:223-232.

5. Anovijay, B., Sayeeganesh, N., Saranyan, R., Jayachandran, D., Priya, K., Subhashini, V. (2015). Periodontal Health Awareness among Medical Students - A Survey. Clin Res Open Access, 1:1-4.

6. Dayakar, M.M., Kumar, J., Pai, G.P., Shivananda, H., Rekha, R. (2016). A survey about awareness of periodontal health among the students of professional colleges in Dakshina Kannada District. J Indian Soc Periodontol, 20:67-71.

7. Ali N.S., Khan, M., Butt, M., Riaz, S. (2012). Implications of practices and perception on oral hygiene in patients attending a tertiary care hospital. J Pak Dent Assoc, 1:20-23.

8. Armitage, C. (1999). "Development of a classification system for periodontal diseases and conditions," Annals of Periodontology, 4(1), 1-6.

9. De, S., Franceschi, L., Fortunato, Carallo, C. (2012). "Periodontal disease and carotid atherosclerosis: mechanisms of the association," in Oral Health Care-Prosthodontics, Periodontology, Biology, Research and Systemic Conditions, InTech, London, UK, 2012

10. Ovadia, R., Zirdok., \& Diaz-Romero, R. M. (2007). "Pregnancy outcomes influenced by periodontitis," Medicine and Biology, 14, 1,10 14.

11. Silness., \& H. Loe. (1964). "Periodontal disease in pregnancy II. Correlation between oral hygiene and periodontal condition," Journal Acta Odontologica Scandinavica, 22, 1: 121-135.

12. Guinness World Records (Eds.) (2001). Gum disease. In: Guinness World Records. New York: Mint Publishers, Incorporated, 175

13. GBD 2015 Disease and Injury Incidence and Prevalence Collaborators. (2016). Global, regional, and national incidence, prevalence, and years lived with disability for 310 diseases and injuries, 1990-2015: a systematic analysis for the Global Burden of Disease Study 2015. Lancet, 388, 1545-1602.

14. Jin, L. J., Lamster, I. B., Greenspan, J. S., Pitts, N. B., Scully, C., \& Warnakulasuriya, S. (2016). Global burden of oral diseases: Emerging concepts, management and interplay with systemic health. Oral Diseases, 22, 609-619

15. Jepsen, S., Berglundh, T., Genco, R., Aass, A. M., Demirel, K., Derks, J., Zitzmann, N. U. (2015). Primary prevention of peri-implantitis: Managing periimplant mucositis. Journal of Clinical Periodontology, 42(Suppl 16), S152-S157.

16. Chapple, I.L. (2014). Time to take periodontitis seriously. British Medical Journal, 348, g2645

17. Pihlstrom, B.L., Michalowicz, B.S., \& Johnson, N.W. (2005). Periodontal diseases. Lancet, 366 , 1809-1820.

18. Sanz, M., Bäumer, A., Buduneli, N., Dommisch, H., Farina, R., Kononen, E., Winkel, E. (2015). Effect of professional mechanical plaque removal Journal of Clinical Periodontology, 42(Suppl 16), S214-S220. 